CIVICS EDUCATION AND SOCIAL SCIENSE JOURNAL(CESSJ)

Volume 2 Nomor 2 Edisi Bulan Desember 2020

\title{
SOSIALISASI PEMBUKUAN SEDERHANA PADA UKM PERIKANAN BANGKIT KAMPUNG PERIKANAN MAMBORO KOTA PALU
}

\author{
Penulis \\ ${ }^{1)}$ Abdul Kahar, ${ }^{2)}$ Tenripada, ${ }^{3)}$ Muhammad Darma Halwi \\ ${ }^{1,2,3)}$ Program Studi Akuntansi Fakultas Ekonomi dan Bisnis \\ Universitas Tadulako \\ *Email: kaharabdu1987@gmail.com \\ *Email: tenripada@untad.ac.id
}

\begin{abstract}
ABSTRAK
UU No 20 tahun 2008 mengatur tentang UMKM mengatur tentang Usaha Mikro Kecil dan Menengah (UMKM). Kontribusi UMKM dalam perekonomian nasional memiliki peranan yang sangat strategis dan menjadi kekuatan ekonomi rakyat dalam mendukung pertumbuhan dan pemulihan ekonomi daerah maupun nasional dalam menghadapi berbagai masalah. Namun kisah sukses beberapa UMKM masih dibarengi dengan kendala seperti keterbatasan akses pembiayaan. Keterbatasan akses pembiayaan bagi pengembangan UKM di Kota Palu perlu mendapat perhatian dari berbagai pihak termasuk kalangan akademisi. Sebagai pihak yang memiliki pengetahuan di bidang ekonomi Akuntansi, kami selaku dosen UNTAD Jurusan Akuntansi Prodi S1, merasa bertanggungjawab untuk melakukan pengabdian kepada masyarakat dalam bentuk kegiatan Sosialisasi Pembukuan Sederhana sebagai upaya peningkatan pengetahuan dan pemahaman peran Laporan keuangan untuk memperoleh pendanaan. Mitra kegiatan sosialisasi ini adalah Anggota kelompok UKM Ikan Asin Perikanan Bangkit Mamboro Kota Palu yang berjumlah 25 orang. Kegiatan sosialisasi dilakukan melalui dua sesi yakni ceramah yang dibarengi dengan pemberian contoh pembukuan sederhana pada usaha ikan kering. Sesi selanjutnya adalah diskusi dimana Tim pengabdi menemukan bahwa faktor yang mendasari keterbatasan permodalan adalah belum adanya pencatatan yang baik pada usaha ikan kering yang mereka geluti baik pada saat poduksi maupun pada tahap penjualan. Hal ini menyebabkan mereka tidak mengetahui jumlah peningkatan hasil usaha yang sesungguhnya mereka peroleh. Melalui pengabdian ini, mereka mengetahui peran penting laporan keuangan dan memahami beberapa bentuk pembukuan sederhana. Tim pengabdi berharap agar para pelaku UKM di Kota Palu memperoleh pelatihan yang berkelanjutan baik dari sisi produksi maupun tata kelola yang mencakup pencatatan transaksi ekonomi.
\end{abstract}

Kata Kunci : UKM, Pembukuan Sederhana, Harga Pokok Produk. 


\title{
SOCIALIZATION OF SIMPLE BOOKINGS ON FISHERY SMEs, KAMPUNG PERIKANAN MAMBORO, PALU CITY
}

\author{
Author \\ Abdul Kahar', Tenripada ${ }^{2}$ Muhammad Darma Halwi ${ }^{3}$ \\ Accounting Study Program, Faculty of Economics and Business Tadulako University \\ Email: kaharabdul987@gmail.com \\ Email: tenripada@untad.ac.id
}

\begin{abstract}
Law No. 20 of 2008 regulates MSMEs regulates Micro, Small and Medium Enterprises (MSMEs). The contribution of MSMEs to the national economy plays a very strategic role and becomes the people's economic strength in supporting regional and national economic growth and recovery in facing various problems. However, the success stories of several MSMEs are still accompanied by obstacles such as limited access to finance. Limited access to finance for the development of SMEs in Palu City needs the attention of various parties, including academics. As parties who have knowledge in the field of Accounting economics, we as lecturers of UNTAD Accounting Department for S1 Study Program, are responsible for carrying out community service in the form of Simple Bookkeeping Socialization activities as an effort to increase knowledge and understanding of the role of financial statements to obtain funding. The partners of this outreach activity were 25 members of the Salted Fish Fisheries SMEs, Bangkit Mamboro, Palu City. The socialization activity was carried out in two sessions, namely a lecture which was accompanied by providing examples of simple bookkeeping in the dry fish business. The next session was a discussion where the service team found that the factor underlying their limited capital was the absence of good records on the dry fish business they were involved in both during production and at the sales stage. This results in them not knowing the amount of increase in business results they are actually getting. Through this service, they know the important role of financial reports and understand some simple forms of bookkeeping. The service team hopes that SMEs players in Palu City will receive continuous training both in terms of production and governance which includes recording economic transactions.
\end{abstract}

Keywords: SMEs, Simple Bookkeeping, Cost of Product. 
CIVICS EDUCATION AND SOCIAL SCIENSE JOURNAL(CESSJ)

Volume 2 Nomor 2 Edisi Bulan Desember 2020

\section{PENDAHULUAN}

Usaha Mikro Kecil dan Menengah (UMKM) tidak dapat dianggap sepeleh terutama dalam perekonomian nasional. UMKM telah berhasil menunjukkan kekuatan ekonomi rakyat dalam menghadapi dan mengatasi berbagai masalah yang perekonomian baik di daerah maupun nasional.

Begitu pentingnya peranan UMKM pada perekonomian di Indonesia, maka pemerintah mengeluarkan Undang-Undang Republik Indonesia Nomor 20 Tahun 2008 yang mengatur Tentang Usaha Mikro, Kecil, dan Menengah. Sektor UMKM telah menyerap lebih dari 90 persen tenaga kerja Indonesia. Sementara, menurut Menteri Koordinator Bidang Perekonomian Airlangga Hartarto, pekerja pada sektor UMKM sebanyak 116 juta orang. Selain itu, Data Kementerian Koperasi dan UMKM, PDB 2017 menunjukkan kontribusi UMKM sebesar 60,34 persen. Kontribusi ini masih dapat ditingkatkan. UMKM terbukti tahan banting menghadapi krisis seperti yang pernah terjadi pada 2012 dan pelambatan pertumbuhan yang terjadi pada 2015 (Purba, 2019).

Sementara itu, Pemerintah Kota Palu melalui Dinas Koperasi, UMKM dan Tenaga Kerja memprediksi jumlah usaha mikro di tahun 2019 lebih dari 6.800. Sedangkan, pelaku usaha mikro yang terdampak bencana 28 September 2018 silam sekitar 1.200. Jumlah ini belum semua terdata karena banyaknya pelaku usaha yang tidak melaporkan. Berdasarkan data Dinas Koperasi dan UMKM dan Tenaga Kerja Kota Palu sampai dengan tahun 2020 terdapat 2.155 pelaku usaha Mikro di Kota Palu. Dari 2.155 pelaku usaha mikro yang terdata di Palu, baru sekitar 1.950 pelaku usaha yang masuk di Sistem Informasi Kredit Program (SIKP) (Ridwan, 2020). Menurut Kepala Dinas Dinas Koperasi dan UMKM dan Tenaga Kerja Kota Palu situasi saat ini pertumbuhan UMKM diprediksi baru bisa meningkat sekitar 20 hingga 30 persen karena keterbatasan permodalan masih (Yolandha, 2020).

Sebagai penggerak motor perekonomian nasional, UMKM di Indonesia ternyata sulit berkembang. Faktor penyebab utama adalah keterbatasan akses pembiayaan dan pemasaran, serta tidak terintegrasinya rantai pasok ke sektor industri (Purba, 2019).

Keterbatasan permodalan bagi pelaku UMKM adalah masalah yang juga dihadapi oleh para pelaku usaha UKM khususnya di Kota Palu pasca peristiwa gempa, likuifaksi dan tsunami. Salah satunya yang terdampak adalah wilayah Kecamatan Palu Utara yaitu Kelurahan Mamboro Barat dikenal dengan sebutan Kampung Perikanan Mamboro.

Bencana Tsunami yang terjadi tanggal 28 September 2018 juga menyebabkan wilayah Kelurahan Mamboro Barat khususnya telah rata dengan tanah. Akibatnya, warga tidak hanya kehilangan tempat tinggal dan anggota keluarga, tapi juga mata pencaharian dan tempat usahapun menjadi korban. Mata pencaharian utama dari warga Mamboro Barat adalah nelayan, pedagang ikan segar dan usaha ikan asin. Meskipun telah ditetapkan sebagai Zona rawan tsunami yang tidak bisa dijadikan sebagai tempat hunian tetap, warga Mamboro Barat tetap berusaha mencari mata pencaharian mereka di lokasi tersebut.

JORNAL PROGDI PPKn, FKIP UNIVET BANTARA SUKOHARJO BEKERJA SAMA DENGANASSOSIASI PROFESI PENDIDIKAN PANCASILA DAN KEWARGANEGARAAN (AP3KNI) JAWA TENGAH 
Untuk memulai kembali usaha dari nol memerlukan modal yang tidak sedikit. Bantuan bagi pelaku UKM berupa stimulan yang berasal dari Pemerintah maupun beberapa Organisasi lebih difokuskan pada penyediaan peralatan dan bahan baku diantaranya perahu, kulkas dan box penyimpanan ikan serta ikan mentah sebagai modal awal usaha. Keterbatasan modal yang diperoleh tersebut memerlukan pengelolaan yang tepat untuk memperoleh hasil maksimal. Alternatif lain yang dapat dipilih untuk pengembangan usaha mereka adalah memperoleh tambahan modal dalam bentuk uang dari lembaga permodalan dan perbankan. Alternatif ini tentunya memiliki persyaratan-persyaratan administratif seperti proposal atau laporan transaksi keuangan yang pada umumnya belum dimiliki oleh pelaku UKM (Ferdiani, 2019).

Beberapa kegiatan Pengabdian Kepada Masyarakat (PKM) terkait dengan Pembukuan Sederhana telah dilakukan. Ningrum, dkk (2019) melakukan pengabdian pada ibu-ibu pengusaha catering. Hasil pelatihan pembukuan sederhana tersebut menumbuhkan kesadaran bagi UMKM tentang pentingnya pelaporan perpajakan pada suatu usaha melalui pembukuan sederhana. Selain itu melalui pembukuan dapat menciptakan pengelolaan manajemen yang baik sehingga berdampak pada peningkatan usaha catering.

Selanjutnya pengabdian dengan judul Sosialisasi Penyusunan Laporan Keuangan Akuntansi Bagi Usaha Kelompok Industri Rumah Tangga Kecamatan Landasan Ulin Kota Banjarbaru menunjukkan pemahaman peserta tentang teori akuntansi dasar dan mereka mampu mengaplikasikan penyusunan laporan keuangan sederhana pada bisnis mereka (Candra et al., 2019).

Pengabdian serupa juga dilakukan oleh Nabil, et. al (2020) kepada pada usaha makanan ringan berbahan dasar singkong dengan sebutan ceriping pada masyarakat di Desa Madisari, Kecamatan Parakan, Kabupaten Temanggung. Pengabdian ini yang bertujuan untuk memperbaiki kondisi UMKM yang terpuruk karena terdampak COVID-19. Hasil pengabdian menunjukkan bahwa para pelaku usaha mendapat pengetahuan tentang bagaimana membuat pembukuan keuangan dalam menjalankan usaha mereka.

Kebutuhan laporan transaksi keuangan tentunya menjadi hal yang merepotkan bagi pelaku UKM ketika mereka tidak memiliki pengetahuan dan pemahaman tentang arti penting laporan transaksi tersebut. Melihat hal ini, maka kami dari pihak akademisi ingin berkontribusi bagi masyarakat di lingkungan sekitar dalam hal ini warga Kampung Perikanan Mamboro Barat dengan cara melakukan kegiatan pengabdian kepada masyarakat melalui kegiatan sosialisasi pembukuan sederhana akuntansi bagi pelaku UKM Ikan Asin Perikanan Bangkit Mamboro Barat. 
CIVICS EDUCATION AND SOCIAL SCIENSE JOURNAL(CESSJ)

Volume 2 Nomor 2 Edisi Bulan Desember 2020

\section{METODE}

Metode yang digunakan dalam pelaksanaan kegiatan PKM ini adalah melalui dua metode yakni sosialisasi peranan pembukuan sederhana bagi perkembangan UKM serta memberikan percontohan dalam perhitungan biaya produksi pada usaha ikan kering serta contoh perhitungan biaya produksi yang dikeluarkan selama satu kali proses produksi. Metode ini dilakukan dengan cara ceramah yang disertai dengan diskusi seputar permasalahan atau kendala yang dihadapi UKM mitra.

\section{HASIL PENELITIAN DAN PEMBAHASAN}

Sebagaian wilayah Kecamatan Palu Utara berbatasan langsung dengan laut dan merupakan daerah pesisir. Kondisi secara geografis yang terletak di daerah pesisir laut menyebabkan sebagian dari warga kecamatan Palu Utara bergerak di bidang perikanan bahkan di Kecamatan Palu Utara terdapat Rumah Tangga Perikanan (RTP). Beberapa kelurahan yang memiliki potensi perikanan diantaranya Kelurahan Taipa, Kelurahan Kayumalue Pajeko dan Kelurahan Mamboro Barat. Kelurahan Mamboro Barat dikenal dengan sebutan Kampung Perikanan Mamboro.

Berdasarkan hasil wawancara yang dilakukan dengan Ketua RT Kampung Perikanan Mamboro terdapat 120 Kepala Keluarga dimana 90\% mata pencaharian utama warga mereka bergerak di bidang perikanan yang terbagi pada beberapa usaha yaitu sebagai pemilik bagan ikan, nelayan, pedagang ikan keliling, penjemur ikan kering serta pemilik usaha ikan asin. $10 \%$ sisanya adalah pekerja serabutan yaitu sebagai penggulung tali rafiah.

Salah satu Usaha Kecil Menengah yang bergerak di usaha ikan asin di Kampung Perikanan Mamboro adalah UKM Perikanan Bangkit yang beranggotakan 25 orang. Mereka telah memperoleh bantuan stimulan baik dari pemerintah maupun bantuan organisasi relawan dalam bentuk pemberian peralatan dan bahan baku. Keterbatasan modal untuk pengembangan usaha menjadi kendala bagi mereka ketika alternatif bantuan dana harus mereka dapatkan dari lembaga permodalan atau perbankan yang membutuhkan persyaratan adminitratif. Sehingga masalah utama yang dihadapi dalam usaha ikan asin UKM Perikanan Bangkit adalah:

1. Belum adanya pemahaman pentingnya pencatatan atas setiap usaha.

2. Belum memiliki pengetahuan tentang pembukuan sederhana bagi UKM.

Untuk mengatasi hal tersebut di atas, melalui kegiatan sosialisasi tim pengabdi menyampaikan beberapa materi pokok yakni pengertian dan manfaat pembukuan sederhana, elemen dalam laporan keuangan sederhana bagi UKM, elemen pembentuk biaya produksi. Pada tahap ini, salah satu materi yang dijelaskan oleh Tim Pengabdi adalah perlunya pemahaman pentingnya pemisahan Aset yang dimiliki usaha (Entitas) dengan harta milik pribadi di luar usaha. Terkait dengan materi bentuk dan elemen laporan keuangan sederhana, Tim 
memberikan materi dalam bentuk pemaparan contoh tabel-tabel pencatatan transaksi serta cara pengisian tabel. Gambar 1 berikut ini adalah contoh perhitungan harga pokok produksi pada usaha ikan asin untuk satu kali proses produksi. Kartu ini juga berfungsi untuk memudahkan para pengusaha (produsen) dalam menentukan berapa biaya yang dikeluarkan setiap pengerjaan suatu pesanan atau proses produksi dilakukan.

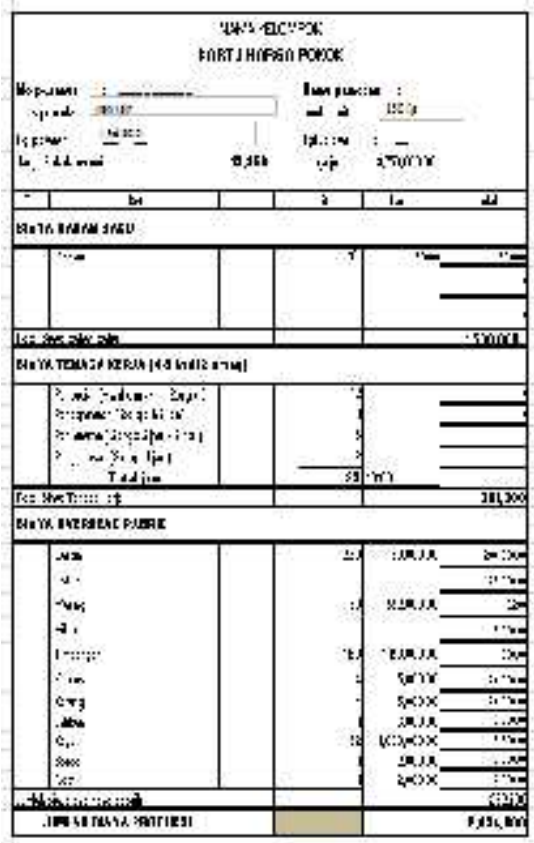

Gambar 1

Kartu Harga Pokok Produksi

Selain pemaparan contoh Kartu Harga Pokok Produksi, tim juga memaparkan contoh Buku Kas (Gambar 2) untuk melihat aliran Kas Masuk dan Aliran Kas Keluar yang terjadi pada kegiatan usaha mereka. Gambar 3 menunjukkan Buku Persediaan yang berfungsi untuk membantu mereka dalam melihat arus keluar masuk persediaan bahan baku.

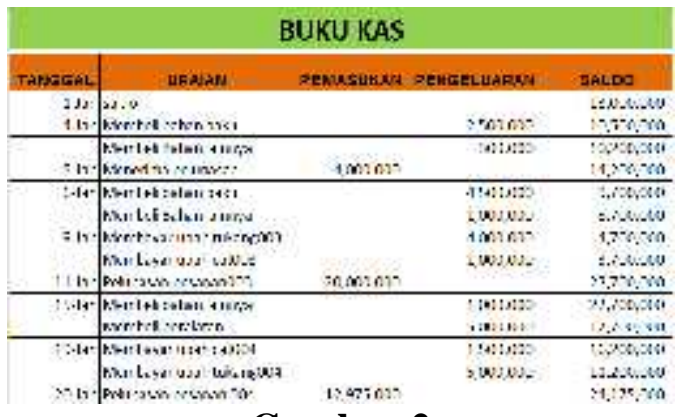

Gambar 2

Buku Kas

JORNAL PROGDI PPKn, FKIP UNIVET BANTARA SUKOHARJO BEKERJA SAMA DENGANASSOSIASI PROFESI PENDIDIKAN PANCASILA DAN KEWARGANEGARAAN (AP3KNI) JAWA TENGAH 
CIVICS EDUCATION AND SOCIAL SCIENSE JOURNAL(CESSJ)

Volume 2 Nomor 2 Edisi Bulan Desember 2020

\begin{tabular}{|c|c|c|c|c|c|}
\hline \multicolumn{6}{|c|}{ BJKU PERSED GAII BAHAN LAININYA } \\
\hline \multicolumn{2}{|l|}{ pembelian } & \multicolumn{2}{|c|}{ pemaksian } & \multicolumn{2}{|l|}{ sise } \\
\hline TANBGRL kuantitas hargs unit & Jumlah keantitzs & harga unit & Jumlah & kuantitas hergaunit & Jumian \\
\hline 1 & & & & & 1,0000 \\
\hline 4 & $36 c 0 x$ & & & & $1,30,000$ \\
\hline 6 & $1000,0 x$ & & & & $i_{3}, 30,000$ \\
\hline 9 & & & $1,00,00$ & & $1,30, \infty 0$ \\
\hline : & & & $1,00,000$ & & $x y 00$ \\
\hline 99 & 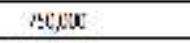 & & & & 1,$6 ; 0 ; 000$ \\
\hline$y$ & Dhaga: & & & & F, thilatial \\
\hline M & & & mase & & maxial \\
\hline
\end{tabular}

Gambar 3

Buku Persediaan Bahan Baku

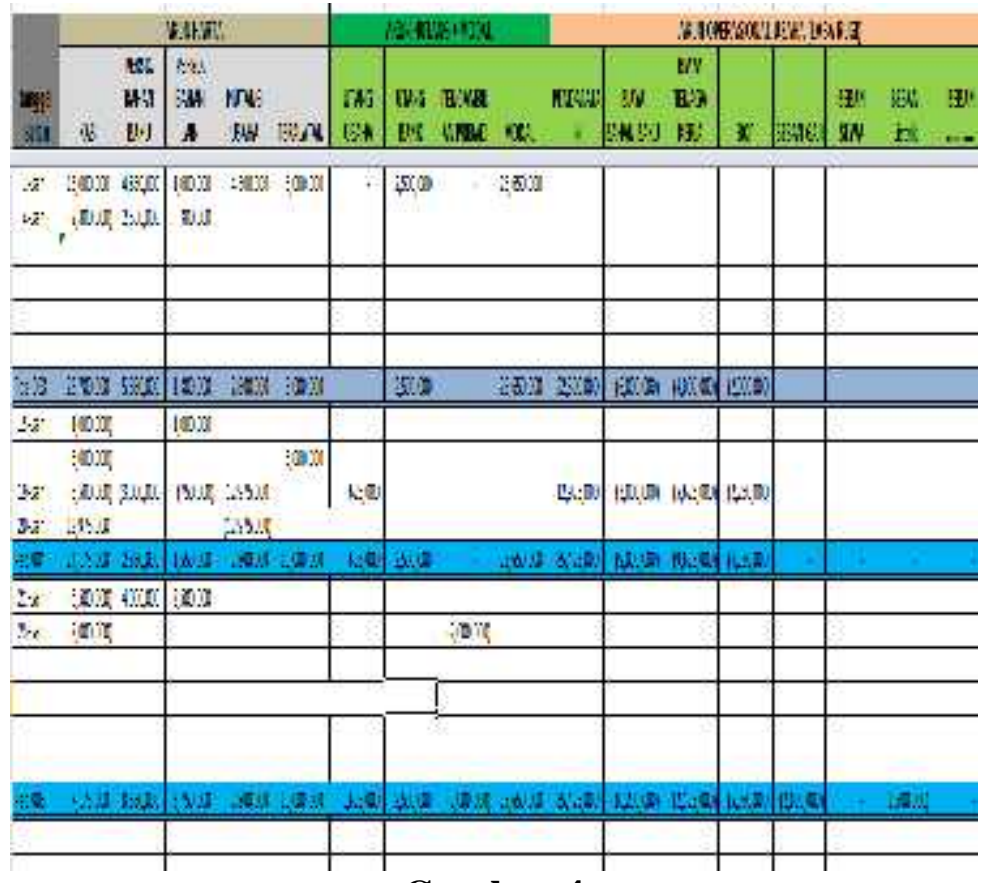

Gambar 4

Kertas Kerja

Selanjutnya, dalam ilmu akuntansi kertas kerja sebagaimana yang dicontohkan pada Gambar 4 dikenal dengan istilah neraca lajur. Namun tim pengabdi membuat contoh kertas kerja yang lebih sederhana sehingga memudahkan mereka dalam menyusun laporan keuangan. Mengingat keterbatasan waktu sosialisasi serta kepadatan materi yang disampaikan tim pengabdi hanya menyampaikan bahwa laporan keuangan pada umumnya terdiri dari Neraca yang menggambarkan posisi Aset/ harta, posisi Hutang dan Modal. Sementara Laporan Laba Rugi menggambarkan Laba yang diperoleh dari hasil pendapatan usaha (penjualan produk) dikurangi dengan biaya yang dikeluarkan yang dapat dilihat 
dari kartu harga pokok produk. Terakhir adalah Laporan perubahan modal yang mereka miliki sejak awal sampai dengan akhir periode laporan keuangan.

Selanjutnya pada tahap diskusi, tim menemukan fakta bahwa banyak dari peserta belum melakukan pencatatan transaksi usaha ikan asin mereka. Adapun pencatatan yang mereka lakukan sebatas kas yang masuk dan kas yang keluar. Ini menjadi alasan mendasar kesulitan permodalan yang dihadapi oleh para calon pelaku UKM maupun pelaku UKM. Masalah lain yang dihadapi pelaku usaha adalah tidak adanya pemisahan asset usaha. Ini berdampak pada perhitungan hasil usaha dalam hal posisi perubahan ekuitas (modal usaha). Selama ini, hasil usaha ikan asin yang mereka peroleh tidak menunjukkan hasil usaha yang sesungguhnya karena belum adanya pemisahan entitas usaha dengan kekayaan pribadi. Belum ada pencatatan yang terpisah antara harta pribadi yang ada sebelum melakukan usaha dan harta yang diperoleh dari usaha. Selain itu, hasil usaha dari ikan asin digunakan untuk pembiayaan kebutuhan rumah tangga tanpa proses pencatatan yang benar (dalam akuntansi, pengambilan pribadi disebut sebagai prive) padahal ini berdampak pada informasi keuangan tentang perubahan modal usaha di akhir periode.

Pembahasan materi penentuan elemen pembentuk harga pokok produksi, timbul beberapa pertanyaan tentang elemen-elemen yang diperhitungkan sebagai harga pokok produk pada usaha ikan asin mereka. Hal ini sangat menarik perhatian Tim, karena banyak dari mereka yang belum memasukkan beberapa elemen sebagai biaya produksi sehingga keuntungan yang mereka dapatkan selama ini belum menggambarkan keadaan yang sesungguhnya karena keuntungan yang mereka perhitungkan lebih tinggi dari yang seharusnya. Sebagai contoh mereka tidak memperhitungkan biaya jika terjadi kerusakan peralatan seperti perahu, alat jemur ikan, kulkas dan peralatan lainnya sehingga tidak ada alokasi biaya depresiasi untuk peralatan tersebut. Penentuan elemen-elemen pada laporan keuangan menjadi penting karena akan dijadikan dasar dalam penentuan harga jual dan perhitungan laba rugi usaha. Beberapa kendala yang dihadapi juga diungkapkan pada sesi diskusi dan tanya jawab. Seperti kendala yang dihadapi ketika jumlah persediaan ikan kering menumpuk sementara tingkat permintaan di pasar mengalami penurunan. Mereka membutuhkan freezer untuk penyimpanan ikan asin yang sudah siap dijual agar kualitas produk ikan asin tetap terjaga. Kebutuhan peralatan ini mempengaruhi harga penjualan ikan asin terutama pada saat persediaan menumpuk.

Hasil sosialisasi pada UKM Ikan Asin Perikanan Bangkit Mamboro Barat menunjukkan:

1. Peningkatan pengetahuan peran penting penyusunan Laporan Keuangan meskipun dalam bentuk pembukuan yang sederhana.

2. Peningkatan pemahaman tentang bentuk pembukuan sederhana yang dapat mereka susun dan

3. Peningkatan pengetahuan tentang dasar penentuan perhitungan harga pokok produk. 
Hasil pengabdian ini menunjukkan hasil yang serupa dengan pengabdian yang dilakukan oleh Ningrum et. al (2019), Candra et. al (2019) yang menunjukkan adanya peningkatan pengetahuan tentang pembukuan sederhana pada pelaku usaha dalam hal ini pelaku UKM. Namun pengabdian ini masih terbatas pada sosialisasi sehingga luaran yang kami harapkan adalah peningkatan pengetahuan dan pemahaman tentang pembukuan sederhana yang diperoleh melalui pemaparan contoh perhitungan pada usaha Ikan Asin yang mereka geluti.

Ini menjadi tantangan bagi kalangan akademisi agar para pelaku UKM benar-benar dapat meningkatkan kesadaran mereka tentang arti penting laporan keuangan melalui pembukuan dalam pengembangan usaha mereka selanjutnya.

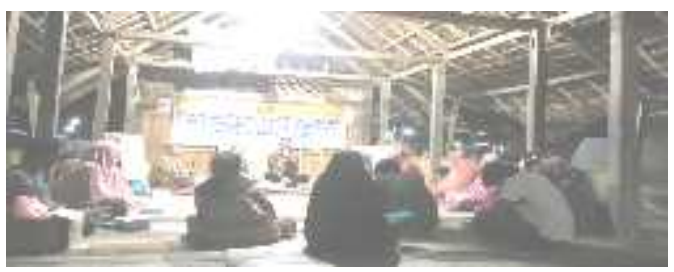

Gambar 5.

Pelaksanaan Kegiatan sosialisasi pembukuan sederhana

\section{SIMPULAN}

Berdasarkan hasil kegiatan pengabdian dalam bentuk Sosialisasi Pembukuan Sederhana pada UKM Ikan Asin Perikanan Bangkit Kampung Perikanan Mamboro Barat Kota Palu menunjukkan peningkatan pengetahuan dan pemahaman tentang manfaat pembukuan sederhana serta bentuk-bentuk laporan keuangan. Mereka mulai memahami Konsep Entitas Bisnis serta mengetahui beberapa bentuk pembukuan sederhana dan komponen pembentuk harga pokok produk usaha ikan asin mereka.

Potensi geografis yang sangat mendukung perkembangan usaha UMKM di Kota Palu khususnya bidang perikanan harus didukung oleh ketersediaan sarana dan prasarana yang maksimal seperti pendanaan (modal) agar tujuan UMKM untuk menciptakan kemandirian secara ekonomi dapat tercapai. Peran akademisi bidang keilmuan Akuntansi masih sangat dibutuhkan dalam bentuk pemberian pelatihan pembukuan secara berkelanjutan bagi pelaku UMKM di Kota Palu.

Pembukuan adalah hal yang merepotkan bagi beberapa pelaku UKM, sehingga dibutuhkan trik dalam pelatihan yang memudahkan pelaku UKM untuk berupaya membuat laporan usaha, yang dilakukan dengan pencatatan manual ataupun pemanfaatan aplikasi pelaporan keuangan dengan menggunakan android. 
CIVICS EDUCATION AND SOCIAL SCIENSE JOURNAL(CESSJ)

Volume 2 Nomor 2 Edisi Bulan Desember 2020

\section{REFERENSI}

Candra, H. K., Iryanie, E., Heldalina, H., \& Wulandari, P. A. (2019). Sosialisasi Penyusunan Laporan Keuangan Akuntansi Bagi Usaha Kelompok Industri Rumah Tangga Kecamatan Landasan Ulin Kota Banjarbaru. Jurnal IMPACT: Implementation and Action, I(1), 74. https://doi.org/10.31961/impact.v1i1.617

Ferdiani, K. R. (2019). Syarat dan Ketentuan Mengajukan Pinjaman Modal untuk $U M K M$.

Www.Modalrakyat.Id. https://www.modalrakyat.id/blog/syarat-dan-ketentuan-mengajukanpinjaman-modal-untuk-umkm

Nabil, M., Arifah, T., Wulansari, A., Tidar, U., Artikel, H., \& Parakan, K. (2020). Pelatihan Pengembangan Pengelolaan dan Pemasaran Bagi Pelaku Pelaku UMKM Ceriping Di Desa Mandisari. ABDIPRAJA: Jurnal Pengabdian Kepada Masyarakat, 1(1).

Ningrum, E. P., Yoganingsing, T., Ratriningtyas, N., Winarso, W., \& Setyawati, N. W. (2019). Pelatihan Pembukuan Sederhana, Sosialisasi Perpajakan dan Pengelolaan Manajemen Bagi UMKM Ibu-Ibu Catering Perumahan Jatimulya RW. 012. Jurnal ABDIMAS UBJ, 02(02), 126-130. https://jurnal.ubharajaya.ac.id/index.php/jabdimas/article/view/126 $130 / \mathrm{pdf}$

Purba, G. N. (2019). Peran UMKM Bagi perekonomian Nasional. Www.Medcom.Id. https://www.medcom.id/ekonomi/mikro/4ba5Vdrbperan-umkm-bagi-perekonomian-nasional

Yolandha, F. (2020). Palu Sebut 60 Persen Omzet UMKM Anjlok Akibat Covid19. Republika.Co.Id. https://republika.co.id/berita/qcn6ao370/palusebut-60-persen-omzet-umkm-anjlok-akibat-covid19 